\title{
PERANCANGAN SISTEM INFORMASI REKAPITULASI KEHADIRAN DOSEN (SIREKAD) BERBASIS WEB PADA UNIVERSITAS DHYANA PURA
}

\author{
Christian Tonyjanto ${ }^{1}$, Gerson Feoh ${ }^{2}$ \\ Program Studi Sistem Informasi ${ }^{1}$, Program Studi Teknik Informatika ${ }^{2}$ \\ Fakultas Ilmu Kesehatan Sains Dan Teknologi \\ Universitas Dhyana Pura ${ }^{12}$. \\ christiantonyjanto@undhirabali.ac.id ${ }^{1}$, gerson.feoh@undhirabali.ac.id ${ }^{2}$
}

\begin{abstract}
Web-based Lecturer Attendance Recapitulation Information System Design (SIREKAD) was designed specifically to meet the application needs in conducting lecturer attendance recapitulation. SIREKAD application is a simple help application to complete the needs of the study program (study program) in monitoring the presence of lecturers. This aims to facilitate data retrieval as a complete study program. Besides that, in the SIREKAD application, other features aside from attendance recapitulation, there is also a space management feature that is useful to facilitate monitoring or evaluation of the learning process and provide information on the existence of classes used by lecturers can be managed properly by the University of Dhyana Pura (Undhira).

KeyWord : Information Systems, Recapitulation, Attendance Report, and Web
\end{abstract}

\begin{abstract}
ABSTRAK
Perancangan Sistem Informasi Rekapitulasi Kehadiran Dosen (SIREKAD) berbasis web dirancang khusus untuk memenuhi kebutuhan aplikasi dalam melakukan rekapitulasi kehadiran dosen. Aplikasi SIREKAD adalah aplikasi bantu sederhana untuk melengkapi kebutuhan dari program studi (prodi) dalam melakukan monitoring terhadap kehadiran dosen. Hal ini bertujuan untuk memudahkan dalam mengambil data sebagai kelengkapan prodi. Selain itu juga didalam aplikasi SIREKAD diberikan fitur lain selain dari rekapitulasi kehadiran ada juga fitur manajemen ruang yang berguna untuk memudahkan monitoring ataupun evaluasi pada proses pembelajaran serta memberikan informasi keberadaan kelas yang dipergunakan oleh dosen bisa di kelola dengan baik oleh Universitas Dhyana Pura (Undhira).
\end{abstract}

Kata kunci:Sistem Informasi, Rekapitulasi, Rekapitulasi Absensi

\section{PENDAHULUAN}

Dalam dunia yang telah berkembang saat ini, khususnya pada Teknologi Informasi telah menjadi hal wajib dalam melengkapi kebutuhan berorganisasi. Web adalah salah satu implementasi dari perkembangan teknologi informasi yang saat ini berkembang pesat. Seiring dengan itu, semakin banyak orang melihat internet sebagai salah satu media informasi yang sangat praktis. Penggunaan web internet pada dunia pendidikan adalah sistem informasi jarak jauh, khususnya bagi masyarakat luas yang ingin mengetahui informasi dari suatu lembaga pendidikan.

Melihat hal itu, Universitas Dhyana Pura sebagai lembaga pendidikan yang saat ini sedang fokus mengembangkan Teknologi
Informasi untuk keperluan kehadiran dalam kegiatan perkuliahan yang dilakukan oleh

Dosen. Selain itu juga berguna untuk membantu rekapitulasi oleh Program Studi (Prodi) untuk melakukan pelaporan dan rekapitulasi kehadiran oleh Program Studi agar memudahkan dalam memberikan pelaporan kepada Bagian Administrasi Akademik (BAA) yang dilakukan setiap bulan oleh Prodi.

Penelitian tentang perancangan sistem informasi rekapitulasi kehadiran dosen berbasis web, bertujuan untuk mengolah administrasi kehadiran dosen yang mengajar pada Prodi dan BAA terhadap rekapitulasi kehadiran dosen pada kegiatan perkuliahan di Universitas Dhyana Pura. pada perancangan sistem informasi yang dilakukan dalam penelitian ini, mengambil 
dasar dari absensi sederhana serta memudahkan setiap program studi melakukan rekapitulasi kehadiran dan pelaporan yang dilakukans setiap bulan.

MODEL, ANALISIS, DESAIN DAN IMPLEMENTASI

\section{Sistem Informasi}

Computer Based Information System (CBIS) atau yang dalam Bahasa Indonesia disebut juga Sistem Informasi Berbasis Komputer me-rupakan sistem pengolah data menjadi sebuah informasi yang berkualitas dan dipergunakan untuk suatu alat bantu pengambilan keputusan. Sistem Informasi yang akurat dan efektif, dalam kenyataannya selalu ber-hubungan dengan istilah "computer-based" atau pengolahan informasi yang berbasis pada komputer. Sistem Informasi "berbasis komputer" mengandung arti bahwa komputer memainkan peranan penting dalam sebuah sistem informasi.

Secara teori, penerapan sebuah Sistem Informasi memang tidak harus menggunakan komputer dalam kegiatannya. Tetapi pada prakteknya tidak mungkin sistem informasi yang sangat kompleks itu dapat berjalan dengan baik jika tanpa adanya komputer. Sistem Informasi me-rupakan sistem pembangkit informasi. Dengan integrasi yang dimiliki antar subsistemnya, sistem informasi akan mampu menyediakan informasi yang berkualitas, tepat, cepat dan akurat sesuai dengan manajemen yang membutuhkannya. (dalam http://repository.usu.ac.id/bitstream/123456789/169 55/4/Chapter\%20II.pdf)

Data

Menurut berbagai kamus bahasa InggrisIndonesia, data di-terjemahkan sebagai istilah yang berasal dari kata "datum" yang berarti fakta atau bahan-bahan keterangan. Data merupakan deskripsi dari sesuatu dan kejadian yang kita hadapi. Data adalah fakta yang jelas lingkup, tempat, dan waktunya. Data diperoleh dari sumber data primer atau sekunder dalam bentuk berita tertulis atau sinyal elektronis. Jadi pada intinya, data merupakan kenyataan yang menggambarkan suatu kejadian dan merupakan kesatuan nyata yang nantinya akan digunakan sebagai bahan dasar suatu informasi.

(http://repository.usu.ac.id/bitstream/123456 789/16955/4/Chapter\%20II.pdf).

\section{Rekapitulasi}

Kinerja
Secara umum istilah kinerja digunakan untuk menyebut prestasi atau tingkat keberhasilan individu maupun kelompok individu. Kinerja adalah gambaran mengenai tingkat pencapaian pelaksanaan suatu kegiatan atau program atau kebijakan dalam mewujudkan sasaran, tujuan, misi, dan visi organisasi yang tertuang dalam strategic planning suatu organisasi. Kinerja bisa diketahui hanya jika individu atau kelompok individu tersebut mempunyai kriteria ke-berhasilan yang telah ditetapkan. Kriteria keberhasilan ini berupa tujuan-tujuan atau target-target tertentu yang hendak dicapai. Tanpa ada tujuan atau target, kinerja seseorang atau organisasi tidak mungkin dapat diketahui karena tidak ada tolak ukurnya (Mohamad Mahsun, 2006: 25).

Pengukuran kinerja adalah proses penilaian kemajuan pekerjaan terhadap tujuan dan sasaran yang telah ditentukan sebelumnya, termasuk informasi atas: efisiensi penggunaan sumber daya dalam menghasilkan barang dan jasa; kualitas barang dan jasa (seberapa baik barang dan jasa diserahkan kepada pelanggan dan sampai seberapa jauh pelanggan terpuaskan); hasil kegiatan di-bandingkan dengan maksud yang diinginkan, dan efektivitas tindakan dalam mencapai tujuan (Robertson, 2002 dalam Mohamad Mahsun, 2006: 25) "feedback from the accountant to management that provides information about how well the actions represent the plans; it also identifies where managers may need to make corrections or adjustment in future planning and controlling activities" Dari definisi-definisi tersebut dapat disimpulkan bahwa pengukuran kinerja adalah tindakan pengukuran yang dilakukan terhadap berbagai aktivitas dalam rantai nilai yang ada pada organisasi (Sony Yuwono dkk, 2004:23). Pengukuran kinerja merupakan salah satu faktor yang amat penting bagi suatu organisasi, pe-ngukuran kinerja menurut Lynch dan Cross (1993) dalam Sony Yuwono dkk (2006:29) bermanfaat untuk:

a. Menelusuri kinerja terhadap harapan pelanggan sehingga akan membawa perusahaan lebih dekat pada pelanggannya dan membuat seluruh orang dalam organisai terlibat dalam upaya memberi kepuasan kepada pelanggan. 
b. Memotivasi pegawai untuk me-lakukan pelayanan sebagai bagian dari mata rantai pelanggan dan pemasok internal.

c. Mengidentifikasi berbagai pemborosan sekaligus mendorong upayaupaya pengurangan terhadap pemborosan tersebut.

d. Membuat suatu tujuan strategis yang biasanya masih kabur menjadi lebihkonkret sehingga mem-percepat proses pembelajaran organisasi.

e. Membangun konsensus untuk melakukan suatu perubahan dengan memberi "reward" atas perilaku yang diharapkan tersebut.

Dari beberapa pengertian dan penjabaran tentang pentingnya pe-ngukuran kinerja yang telah di-kemukakan, dapat disimpulkan bahwa pengukuran kinerja dapat dijadikan sebagai ukuran keberhasilan suatu organisasi dalam kurun waktu tertentu dan hasil pengukuran kinerja dapat dijadikan sebagai masukan untuk per-baikan dan peningkatan organisasi di masa yang akan datang.

\section{Alat pengukuran Kinerja non Keuangan}

Pentingnya pengukuran kinerja non keuangan disebabkan karena organisasi menghadapi perubahan lingkungan secara cepat. Untuk dapat bersaing, organisasi membutuhkan sistem informasi yang berkemampuan me-nangkap informasi secara cepat dan efektif. Meskipun analisis catatan keuangan adalah penting, tetapi perhitungan tersebut kurang me-nyediakan informasi yang akurat mengenai kemampuan organisasi. Informasi yang diukur dalam satuan keuangan merupakan hasil dari keputusan masa lalu.

Dalam menghadapi perubahan lingkungan dan persaingan yang semakin meningkat, pengukuran non keuangan menjadi penting untuk dilakukan karena banyak data-data non keuangan yang bersifat kualitatif yang menyangkut operasional perusahaan maupun yang menyangkut hubungan organisasi dengan lingkungan eksternalnya yang mempunyai pe-ngaruh besar terhadap kelangsungan hidup perusahaan. Dengan kata lain, pengukuran non keuangan merupakan pengukuran atas aktiva tak berwujud dan kapabilitas organisasi yang dapat membantu organisasi untuk mencapai keberhasilan. Aktiva tak berwujud tidak dapat diukur dalam pengukuran keuangan karena tidak dicantumkan dalam laporan keuangan suatu organisasi. Hal ini terjadi karena sulit untuk menghitung nilai finansial aktiva tak berwujud tersebut. Padahal aktiva tak berwujud tersebut mempengaruhi laporan keuangan suatu organisasi dalam penggunaannya.

Ukuran-ukuran non keuangan tidak dapat menggantikan ukuran-ukuran keuangan, keduanya saling melengkapi (Kaplan \& Norton, 2000). Pengukuran kinerja berdasarkan non keuangan akan berhubungan secara langsung dengan strategi bisnis dan dapat berubah sesuai dengan perubahan kondisi lingkungan bisnis. Ukuran-ukuran non keuangan yang bisa digunakan oleh perusahaan antara lain kepuasan pelanggan, loyalitas pelanggan, kemampuan karyawan, proses internal yang responsif dan dapat diprediksi, dan sebagainya. Ukuran-ukuran non keuangan tersebut merupakan aktiva intelektual dan tak berwujud yang dimiliki oleh suatu perusahaan.

\section{Dosen}

Menurut Prof Dede, semua mahasiswa yang memutuskan untuk ambil studi di perguruan tinggi, pasti memiliki anganangan besar dalam dirinya untuk menjadi seseorang yang berbeda dengan mereka yang putus sekolah pada jenjang menengah atau jenjang pendidikan dasar. Sebahagian dari para mahasiswa mungkin ada yang memiliki idealisme untuk menjadi ilmuwan, dan terus menempuh studi pada jenjang strata satu, dua dan tiga, sehingga menjadi seorang ilmwan bergelar akademik Doktor, atau paling tidak bergelar akademik Master. Akan tetapi, pada umumnya mereka berangan-angan untuk menjadi profesional dan dapat mengakses kesempatan kerja sebagai profesional, diterima kerja sebagai profesional, dan memperoleh penghasilan yang layak sebagai seorang profesional. Untuk itu, mereka harus terlahir sebagai sarjana yang cerdas dan berdaya saing. Angan-angan tersebut, dimiliki oleh hampir semua mahasiswa. Oleh sebab itu, ketika membaca brosur dan informasi program studi, mereka akan men-cermati profile dari program studi tersebut serta nama-nama dosen pengampu mata kuliah pada program studi yang mereka minati itu. Program studi paling besar jumlah Guru Besar, atau Doktornya, dan memiliki captive market yang bagus, pasti akan mem-peroleh peminat paling besar dari seluruh calon 
mahasiswa. Jika tidak terpenuhi ketigatiganya, maka akan secara gradual turun pada dua kriteria, sampai hanya pada satu kriteria saja.

Penilaian para pengguna baik sebagai pemakai lulusan maupun sebagai pelanggan jasa layanan pendidikan, merupakan masukan yang amat berharga bagi universitas untuk terus meningkatkan kualitas layanan, agar senantiasa terus meningkatkan kualitas proses pendidikan untuk menghasilkan lulusan cerdas berdaya saing. Ukuran cerdas berdaya saing bagi lulusan sarjana strata satu adalah penyerapan pasar kerja. Semakin cepat seorang sarjana terserap pasar tenaga kerja, maka semakin berkualitas kesarjanaan nya, dan semakin ber-kualitas pula institusi yang melahirkannya. Setidaknya ada tiga jalur penyerapan, pertama, wira usaha, yakni kemampuan entrepreneurship dari seorang sarjana untuk me-ngembangkan wira usaha mandiri, dalam sektor apa saja kegiatan bisnis mereka, patut dihargai, dan ini adalah lulusan yang paling berkualitas. Kemudian kedua, masuk pasar kerja yang linier dengan bidang ilmunya, contoh alumni Tarbiyah yang menjadi guru, alumni syari'ah yang menjadi hakim agama, atau pengacara untuk kasus-kasus yang menjadi kewenangan Peradilan Agama, alumni fakultas da'wah yang menjadi da'i, alumni perbankan syari'ah yang menjadi pegawai bank syari'ah. Kemudian ketiga, masuk pasar kerja yang tidak sesuai dengan keahlian keilmuannya, tapi menjadi orang sukses dalam bidang dimasukinya itu, seperti alumni Akidah Falsafat yang menjadi politisi di DPR, atau DPRD. Alumni tafsir yang menjadi Bupati atau Gubernur. Alumni tarbiyah yang menjadi penguasa. Dan UIN, IAIN serta STAIN adalah lembaga pendidikan yang sukses mengantarkan para alumninya untuk menjadi orang sukses di luar keahliannya itu.

Kunci sukses mereka adalah dosen yang memiliki tiga kualifikasi utama, yakni memiliki kapabilitas, loyalitas ${ }^{[1]}$ dan akuntabilitas. Seorang dosen harus memiliki kapabilitas yang baik dalam bidang keilmuannya, dan itu ditandai dengan pendidikan yang linier dengan cabang atau bidang ilmu yang akan menjadi tanggungjawabnya, kemudian, produktif dalam menulis paper dalam bidang ilmunya itu, baik untuk bahan ajar maupun paper untuk disampaikan dalam forum seminar atau simposium, dan bahkan pada jenjang kepangkatan untuk memperoleh Guru Besar, seorang dosen harus menulis sebuah buku akademik yang tidak terikat dengan silabus perkuliahan. Kemudian dosen harus memiliki loyalitas yang baik, karena dosen yang pintar tidak akan bisa menghantarkan para mahasiswanya menjadi pintar, jika dia tidak pernah masuk kelas, atau masuk kelas hanya dua kali di awal dan di akhir semester, sementara 12 kali pertemuan lainnya, para mahasiswa hanya didampingi para asisten yang baru lulus master, maka para mahasiswa akan menjadi sarjana yang premature, karena dibina dan dididik bukan oleh Guru Besarnya, atau pengamu utama mata kuliah tersebut. Atau dosen itu masuk 14 kali dalm satu semester, tapi para mahasiswa tidak dibimbing untuk pengembangan keilmuannya dengan tugastugas mandiri yang seharusnya diberikan mingguan, maka mahasiswa akan menjadi sarjana yang akan kalah bersaing di pasar tenaga kerja oleh sarjana lain dari universitas lain. Kemudian dosen juga harus akuntabel, yakni masuk 14 kali persemester, dan di kelas mereka mengajar atau mendampingi para mahasiswanya belajar, bukan menggunjingi presiden, menteri, para anggota DPR atau bahkan menggunjingi pimpinan fakultas dan universitas. Para mahasiswa masuk kelas siap untuk belajar, bukan siap untuk diajak berfikir negatif tentang orang lain yang akan sangat kontraroduktif untuk menghantarkan mereka menjadi sarjana yang cerdas berdaya saing.

Kunci sukses perkuliahan yang dapat menghantarkan para mahasiswa menjadi sarjana yang cerdas berdaya saing adalah dosen, karena kendati universitas didukung dengan per-pustakaan yang baik, jika tidak digerakkan oleh dosen, para mahasiswa tidak akan dengan optimal memanfaatkan perpustakaan sebagai sumber belajar mereka. Demikian pula dengan laboratorium, jika dosen tidak mendisain perkuliahan yang memanfaatkan laboratorium sebagai sarana pembelajaran, maka keberadaan laboratorium tidak akan membawa manfaat untuk menghantarkan para mahasiswa menjadi sarjana yang cerdas berdaya saing. Begitu pentingnya posisi dosen, Indonesia secara serius meregulasi pelaksanaan tugas dosen, serta jaminan hidup yang disiapkan negara untuk profesi 
mulia tersebut, melalui UU No. 14 tahun 2005 tentang Guru dan Dosen. Dalam Undang-undang tersebut ditegaskan bahwa dosen adalah pendidik profesional dan ilmuwan dengan tugas utama mentransformasikan, me-ngembangkan, dan menyebarluaskan ilmu pengetahuan, tek:nologi, dan seni melalui pendidikan, penelitian, dan pengabdian kepada masyarakat ${ }^{[2]}$. Dosen adalah pendidikan profesional dan ilmuwan, yakni seseorang yang memiliki kapabilitas dalam bidang keilmuan tertentu, dan dengan kapabilitasnya itu, dia bisa mengajar, meneliti untuk mengembangkan teori-teori serta teknologi dalam bidang keilmuannya, dan bahkan melakukan pengabdian pada masyarakat untuk memvalidasi teori atau teknologi yang sudah dihasilkan lewat penelitiannya. Kedudukan dosen, sebagaimana diatur pada pasal 5 UU No. 14 tahun 2005 tentang Guru dan Dosen, ditegaskan bahwa kedudukan dosen sebagai tenaga profesional menjadi agen pembelajaran, pengembang ilmu pengetahuan, teknologi, dan seni, serta pengabdi kepada masyarakat berfungsi untuk meningkatkan mutu pendidikan nasional ${ }^{[3]}$.

\section{Metodologi Penelitian}

Penelitian yang dilakukan melalui beberapa tahapan yang harus dilakukan agar sistem informasi yang dibuat bisa memberikan fasilitas yang mudah bagi program studi dan perguruan tinggi, agar bisa sejalan dengan rencana yang diharapkan. Adapun prosesnya sebagai berikut;

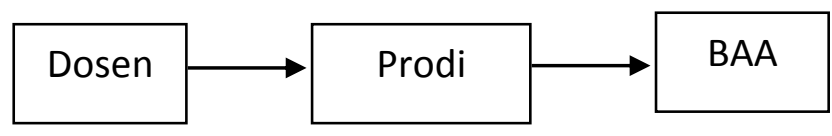

Gambar 1 Alur Proses Rekapitulasi

Dengan penjelasan dari proses sebagai berikut;

\section{Dosen}

Pada Dosen, sebagai penyedia data untuk melengkapi dan mem-persiapkan beberapa data penting seperti identitas dan kelengkapan lainnya.

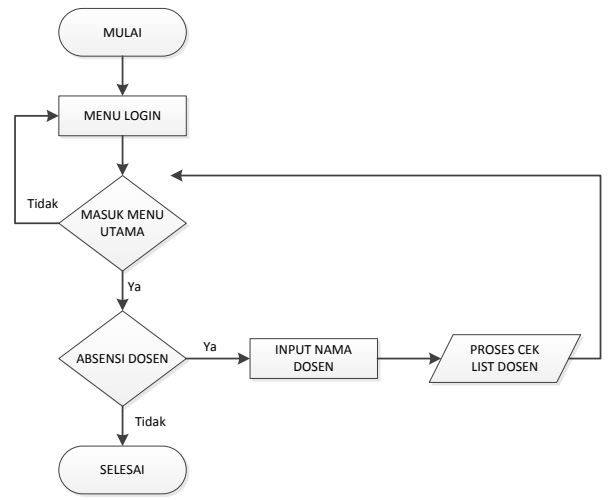

Gambar 2 Alir Absensi Kehadiran Dosen

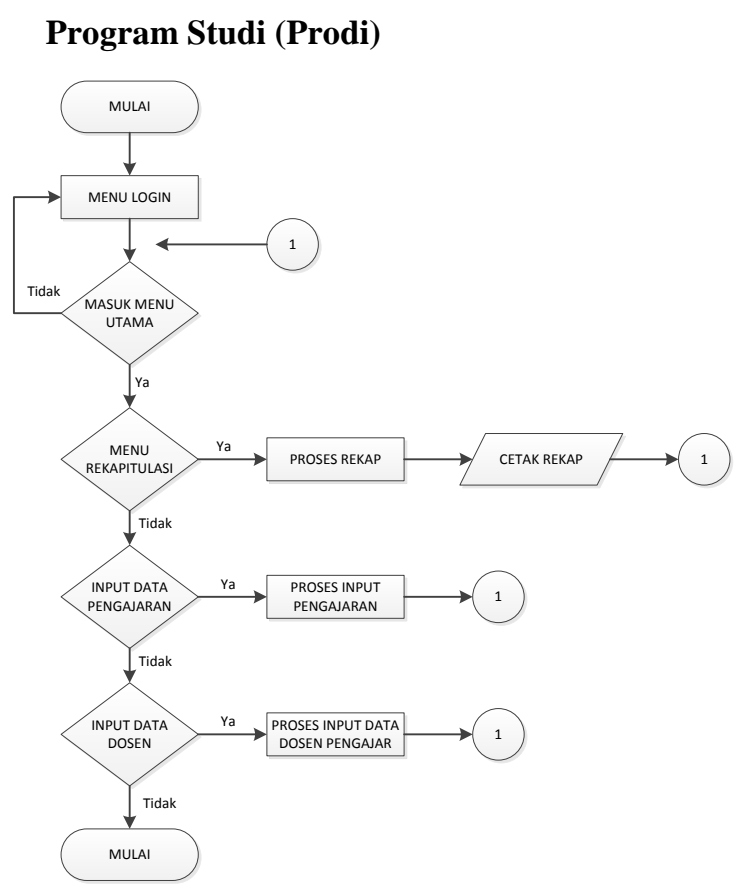

Gambar 3 Diagram Alir Proses Pemeriksaan BAA

Kelengkapan oleh Program Studi

Pada BAA, berfungsi sebagai departemen yang melakukan verifikasi akhir dan pengajuan ke bagian keuangan sebagai proses akhir.

\section{Analisis dan Perancangan Sistem}

Melihat dari hasil analisis pada Gambar 1 dapat dilakukan identifikasi untuk kebutuhan dari perancangan SIREKAD guna membantu proses rekapitulasi kehadiran dosen yang masih dilakukan dengan cara manual. Adapun identifikasi dari kebutuhan sebagai berikut
a. Menyiapkan rancangan sistem rekapitulasi kehadiran dosen
b. Mengidentifikasi berbagai altenatif input data yang diperlukan


c. Mengevaluasi berbagai data yang akan diinput kedalam sistem

d. Memilih konfigurasi terbaik

e. Menyiapkan usulan penerapan

SIREKAD merupakan sistem yang dirancang untuk membantu proses pada Prodi dimana perlu dilakukan rekapitulasi

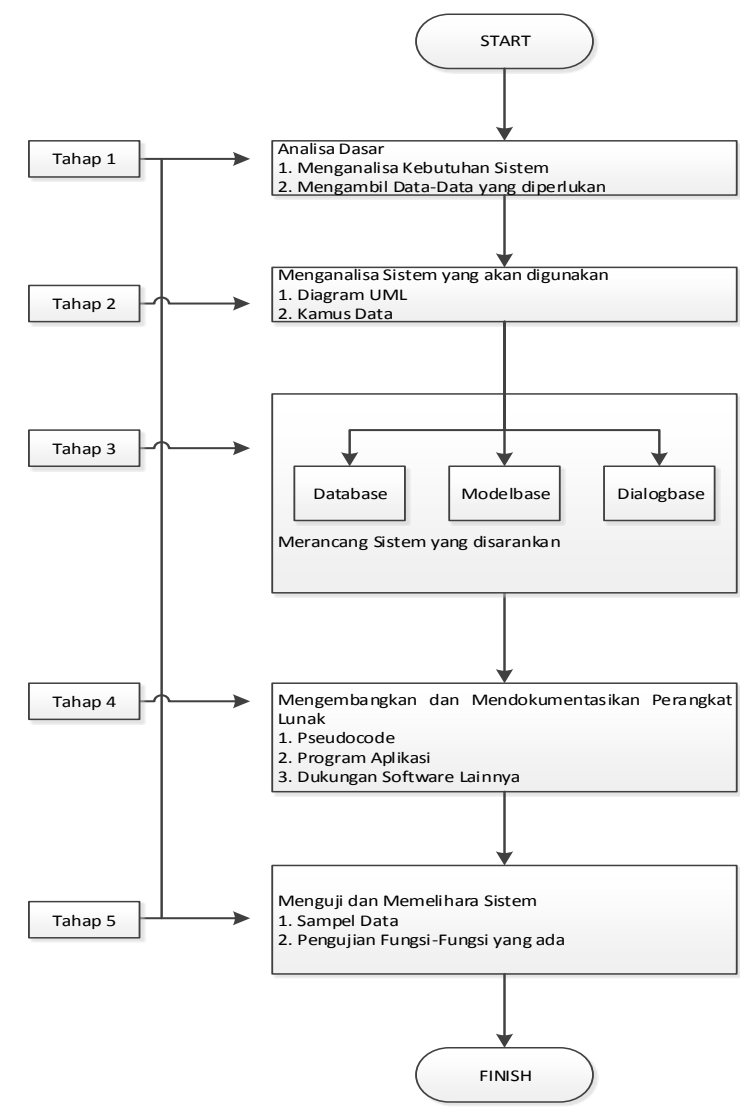

kehadiran dosen dalam mengajar setiap bulannya untuk dapat memonitoring dan melaksanakan evaluasi kehadiran. Dengan melihat hasil akhir dari sistem informasi rekam jejak dosen, perlu sekali dilakukan penerapan teori diagram Unified Modelling Language (UML) yang dikembangkan menjadi kamus data yang berisi seluruh item data yang digunakan.

Gambar 4 Tahapan Perancangan SIREKAD

\section{Hasil dan Pembahasan}

Dari hasil penelitian yang dilakukan dengan menggunakan konsep sistem informasi. Adapun proses perancangan sistem yang dilakukan adalah sebagai berikut;

Model Basis data yang dirancang dalam sistem menggunakan model data logika atau konseptual dan model data fisik. Sebelum membangun model data tersebut terlebih dahulu ditentukan objek yang terdapat dalam sistem. Adapun hasil dari identifikasi sebelumnya melalui kamus data. Obyek-obyek tersebut antara lain;

1. Identitas Dosen

2. Status Penggunaan Ruang Kelas

3. Matakuliah di Program Studi Kegiatan di Program Studi

Dengan dilakukan penentuan obyekobyek tersebut selanjutnya dilakukan organisir dan identifikasi hubungan antar obyek. Menurut kurata(1996), terdapat 3 jenis dasar hubungan antar objek, yaitu :

1.Subkelas

Merupakan hubungan antara kelas objek dengan kelas objek diatasnya, dimana objek-objek ini memiliki properti dan perilaku kelas diatasnya. Hubungan ini diidentifikasi dengan menggunakan klausa "adalah $($ is a $)$ ".

\section{Container (wadah)}

Merupakan hubungan yang terjadi karena suatu objek terbentuk dari objek

lain. Hubungan diidentifikasi dengan menggunakan bahasa klausa "memiliki (has a)"

\section{Kolaborator}

Merupakan hubungan yang terjadi apabila objek perlu menggunakan objek lain untuk tujuan tertentu. Hubungan ini diidentifikasi dengan menggunakan klausa "memakai (use)"

Hubungan yang terjadi antara objek pada perancangan sistem informasi ini adalah hubungan container dan kolaborator. Untuk menggambarkan hubungan antar objek tersebut, selanjutnya dibangun model logika dari basisdata. Model data logika atau model data konseptual menggambarkan struktur logis dari basisdata, serta kardinalitas antar objek. Adapun model data konseptual dari basis data Sistem Rekam Jejak Dosen berbasis web seperti pada gambar 4.x menunjukkan atribut dari masing-masing obyek, hubungan obyek, primary identifier yang secara unik mengidentifikasi obyek serta mandatory yang menyatakan atribut harus berisi data (tidak boleh kosong).

\section{Perancangan Tampilan}


Pada sub bagian ini, dapat ditampilkan rancangan tampilan pengguna dari sistem rekam jejak dosen. Pada tampilan sistem ini menggunakan tema gratis dari bootstrap yang bisa unduh gratis dari internet, serta untuk memudahkan user dalam menggunakan sistem ini.

\section{Perancangan Pencetakan}

Pada perancangan pencetakan ini, yang diutamakan adalah berupa dokumen file berbentuk pdf yang dapat dicetak atau disimpan kedalam komputer dosen untuk keperluan pengajuan kenaikan jabatan akademik.

\section{Perancangan Laporan}

Pada perancangan laporan, tidak ada hasil dalam bentuk cetakan tetapi hasil dalam bentuk tampilan. Hingga saat ini proses masih sedang berjalan.

\section{Tampilan Kehadiran Dosen}

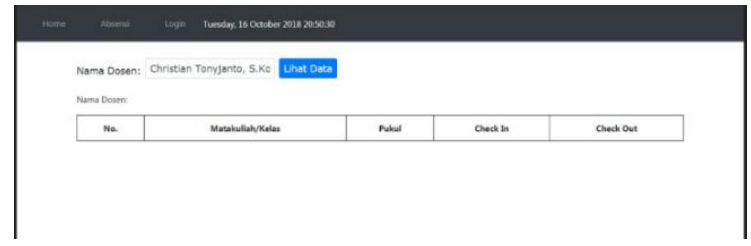

Gambar 5 Tampilan Kehadiran Dosen

Pada tampilan gambar 5 terlihat dari contoh salah satu dosen yang memiliki jadwal mengajar atau tidak mengajar pada hari yang sama dan waktu berlaku. Apabila dosen memasukan nama akan terlihat dimana saja dosen itu mengajar pada hari dan waktu yang berlaku. Untuk saat ini waktu masuk atau cek-in belum diberikan batasan. Dari tampilan ini, sebagai awal untuk dapat melakukan rekapitulasi.

\section{$\underline{\text { Tampilan Rekapitulasi Kehadiran }}$}

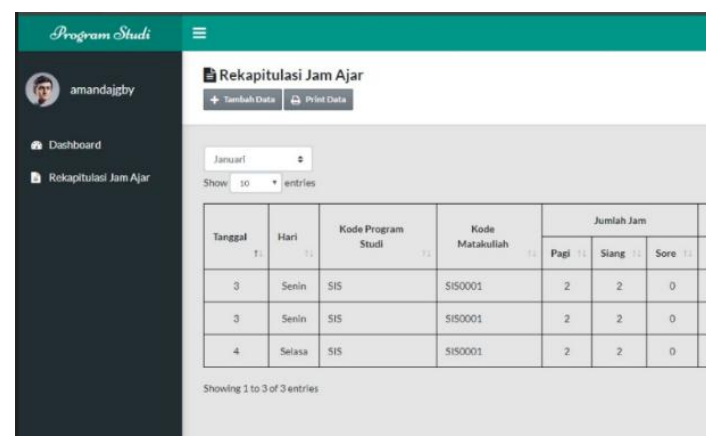

Gambar 6 Tampilan Rekapitulasi Kehadiran

Pada gambar 6 adalah tampilan form hasil rekapitulasi kehadiran yang telah dilakukan oleh Dosen seperti pada Gambar 5 bila dosen tersebut sudah cek-in akan segera tercatat oleh sistem dari sini juga program studi dapat memberikan pelaporan yang harus dilakukan setiap bulannya.

\section{Simpulan}

Dari penelitian yang sudah dilakukan dari sistem yang dibangun mengenai SIREKAD, maka dapat diambil kesimpulan sebagai berikut; Pada Aplikasi SIREKAD, memiliki beberapa fitur yang berhubungan dengan Rekapitulasi Kehadiran Dosen, seperti penggunaan ruangan yang bertujuan agar prodi dapat melakukan monitoring secara langsung. Dengan adanya SIREKAD, kegiatan prodi setiap bulan dapat dilakukan dengan mudah tanpa harus dilakukan dengan manual.

\section{DAFTAR PUSTAKA}

[1] Dewanto, I. Joko., Web Desain (Metode Aplikasi dan Implementasi), Yogyakarta: Graha Ilmu, 2006

[2] Jusak, Teknologi Komunikasi Data Modern., Yogyakarta:Andi Offset, 201

[3] Kadir Abdul, Dasar Pemrograman Web Dinamis Menggunakan PHP, Yogyakarta:Andi Offset, 2003

[4] Komputer, Wahana., Webmaster Series: Menguasai HTML, Yogyakarta:Andi Offset, 2015.

[5] Kendall, System Analysis and Design, $8^{\text {th }}$ Edition, 2013

[6] Mathias Weske, Business Process Management (Concept, Language, Architecture). Springer, 2007

[7] Madcoms, Mahir dalam 7 Hari : Adobe Dreamweaver CS5 dengan Pemrograman PHP \& MySQL., Yogyakarta:Andi Offset, 2011. 
[8] Nugroho, Eko., Sistem Informasi Manajemen, Konsep, Aplikasi dan Perkembangannya., Yogyakarta:Andi Offset, 2013

[9] Rachmawati. [Online]. Tersedia: http://elib.unikom.ac.id/files/disk1/ 527/jbptunikompp-gdl-rachmawati26318-5-unikom_r-i.pdf. [29 September 2012, 17.35 WIB].

[10] Saleh, Abdul Rahman., Membangun Perpustakaan Digital: Step by Step. Jakarta: Sagung Seto, 2010

[11] Saputro, Hendra W. (2007). Pengertian Website dan Unsurunsurnya. [Online].Tersedia: http://www.balebengong.net/topik/t eknologi/2007/08/01/pengertianwebsite-dan-unsur-unsurnya.html. [29 September 2012, 17.30 WIB].

[12] Sianipar, R. H., Dasar Analisis dan Perancangan Pemrograman Berorientasi Objek dengan Java., Yogyakarta:Andi Offset, 2018

[13] Suyanto, Asep Herman., Step by Step: Web Design Theory and Practices. Yogyakarta: Andi Offset, 2007

[14] Prasetya, Andreas Hery., Cepat Kuasai PHP dan MySQL, Yogyakarta:Andi Offset, 2011.

[15] Pressman, Roger S., Rekayasa Perangkat Lunak (Pendekatan Praktis) Edisi 7 : Buku 1, Yogyakarta:Andi Offset, 2012.

[16] TMBooks, Sistem Informasi Akuntasi, Konsep dan Penerapan, Yogyakarta:Andi Offset, 2015.

[17] Yanto, Robi., Manajemen Basis Data Pemodelan, Perancangan dan Penerapan, Yogyakarta:Deepublish, 2017.

[18] Yurindra, Buku Software Engineering, Yogyakarta:Deepublish, 2017.

[19]Zubaidi, Khadafi., Seri Pemrograman PHP di Ubuntu: Membuat Sistem Informasi Kursus Berbasis Web, Yogyakarta:Andi Offset, 2015.
[20]__ . 2012. Definisi dan Pengertian Web Menurut Para Ahli. [Online]. Tersedia: http://www.sambureki.com/definisi /definisi-dan-pengertian-webmenurut-para-ahli.html. [29 September 2012, 17.32 WIB]. 